\title{
Rapid processing of the meaning of sentences
}

\author{
IRA FISCHLER and PAUL A. BLOOM \\ University of Florida, Gainesville, Florida 32611
}

\begin{abstract}
It has been shown (Fischler \& Bloom, 1979) that sentence contexts facilitate a lexical decision task for words that are highly likely sentence completions and inhibit the decision for words that are semantically anomalous sentence completions. In the present experiment, the sentence contexts were presented 1 word at a time, at rates from 4 to 28 words/sec. The facilitation for words that were likely sentence completions was marginal at the slower rates and absent at higher rates. In contrast, the inhibitory effects of semantic anomaly were apparent at all presentation rates. Several analyses suggested that the sentence contexts were becoming ineffective at the very highest presentation rates, but the high rates at which the sentence contexts still affected word recognition were taken as evidence that semantic information accrues at an early stage of sentence processing. Implications for Posner and Snyder's (1975) theory of attention and for models of reading were discussed.
\end{abstract}

For most literate adults, the various skills involved in reading are highly overlearned. Years of practice in visual word recognition, grammatical organization, and semantic analysis enables the reader to obtain an accurate representation of a sentence quite rapidly and with little apparent effort. The recent theoretical separation of automatic and attentional processes (LaBerge, 1976; Posner \& Synder, 1975; Schneider \& Shiffrin, 1977) has renewed interest in various aspects of rapid reading skill. The present paper is concerned with the role of sentence context on word recognition and, more specifically, is an extension of a series of experiments reported previously (Fischler \& Bloom, 1979), in which we have attempted to separate the automatic from the more effortful aspects of how context is used in reading.

\section{Effects of Sentence Contexts on Word Recognition}

Seminal experiments by Morton (1964) and Tulving and Gold (1963) showed that the semantic context of a sentence could indeed influence the subsequent recognition of a word, as measured by visual duration thresholds for identification. Both studies found a reduction in threshold for words that were semantically appropriate and likely completions of a sentence context, with less effect as the Cloze probability (Taylor, 1953) of a word's being a response to the sentence context declined. For instance, the threshold for the word COLLISION was uninfluenced by the prior presentation

This research was supported by National Institute of Mental Health Grant RO3 MH30395 to the first author. We thank Daniel Tumarkin, Eric Nietzke, and Roger Lewis for their assistance in data collection and James Neely for his careful critique of an earlier version of the paper. Results of an earlier stage of the research were reported at the meeting of the Southeastern Psychological Association, Atlanta, Georgia, March 1978. Reprint requests should be sent to Ira Fischler, Psychology Department, University of Florida, Gainesville, Florida 32611. of the context, "Three people were killed in a major highway _.," whereas the threshold for the word ACCIDENT was facilitated. Tulving and Gold (1973) also found that semantically anomalous test words (e.g., COMMUNISM in the above sentence) resulted in substantially higher thresholds.

Semantic priming effects for sentential contexts have also been demonstrated in the lexical decision task, in which subjects are required to indicate whether or not a presented stimulus is a word. Schuberth and Eimas (1977) showed that, compared with a no-prime control condition, sentence contexts reduced latencies to recognize words congruent with the sentence's meaning and increased latency for words incongruent with this meaning. A number of subsequent studies have not only demonstrated both facilitatory and inhibitory effects of sentence context on word recognition latency (Fischler \& Bloom, 1979; Kleiman, 1977; Stanovich \& West, 1979; West \& Stanovich, 1978), but have also determined that the relative amount of inhibition and facilitation depends on a variety of factors: the grade level (West \& Stanovich, 1978) and skill (Perfetti, Goldman, \& Hogaboam, 1979) of the reader, the speed of recognition (Stanovich \& West, 1979) and nature of the recognition task (Fischler \& Bloom, 1979), and the degree to which the context provides useful information about the test word over the experimental session (Fischler \& Bloom, 1979).

\section{Distinguishing Automatic and Attentional Processes}

Since reading is a highly practiced skill, it may be that both the recognition of individual words and the influence of contextual information on word recognition develop into automatic processes. According to Posner and Snyder (1975), a process may be automated when the relation between a stimulus and a particular code or response is habitual and invariant. An automatic process 
is one that is rapidly induced, proceeds without an allocation of attentional capacity from a central processing mechanism, and is not easily modified by the expectations or strategies of the subject.

Each of these postulated characteristics has led to experimental procedures for identifying automatic processes. In the analysis of single-word priming effects on word recognition (e.g., Meyer \& Schvaneveldt, 1971), the separation of automatic from attentional processes has been most clearly shown in the work of Neely (1977). The words used in his experiment were drawn from three semantic categories (e.g., "Robin" from "Bird"). A lexical decision stimulus was preceded by either a word prime or a neutral stimulus (a row of Xs). The word prime was the name of a category (e.g., Bird). The subjects' expectations about the relation between the prime word and possible test words were manipulated. In the no-shift condition, $80 \%$ of the test words on the word-prime/word-test trials were exemplars of the prime-word category (e.g., Bird-ROBIN). In the shift condition, $80 \%$ of the test words were exemplars of a prespecified category other than that represented by the prime word (e.g., Body-DOOR).

Neely (1977) found that if subjects were given sufficient time to process the word prime (c. $700 \mathrm{msec}$ ), latencies to words from the more likely category were facilitated and those to words from the unlikely category were inhibited, compared with the neutral control. Thus, in the shift condition, the word prime inhibited responding to a semantically related but unexpected word. In contrast, when only $250 \mathrm{msec}$ passed between presentation of the prime and test words, latencies to words semantically related to the prime word were facilitated for both the no-shift and shift conditions. Latencies to test words unrelated to the prime showed neither facilitation nor inhibition.

Neely's (1977) experiment demonstrates the procedures commonly used for separating the two kinds of processes: manipulation of a subject's expectancies, variation in the time available for processing the context, and the use of a neutral control condition against which to assess the relative degree of facilitation and inhibition.

The results of Neely's (1977) experiment suggest that both automatic and attentional processes could be influencing the priming effects of single words on lexical decision time (cf. Fischler, 1977; Tweedy, Lapinski, \& Schvaneveldt, 1977). According to Posner and Snyder (1975), the occurrence of facilitation in the absence of a corresponding inhibition for other events implicates an automatic process. With only $250 \mathrm{msec}$ to process the prime word, subjects are unable to direct attention to the more likely category, and facilitation is limited to those words automatically activated by the prime word At the longer delays, the limited-capacity attentional system produces facilitation for words from the expected categories, but at a cost of inhibiting responses to words from unexpected categories.
The presence of inhibition along with facilitation in the effects of sentence contexts on identification thresholds (Tulving \& Gold, 1963) and on speeded lexical decision latency (Schuberth \& Eimas, 1977) thus suggests that attentional factors do play a role in the contextual effects of sentences on word recognition. West and Stanovich (1978) found that, for adults, facilitation may be produced without corresponding inhibition, but this inhibition reappears if the recognition of the test word itself is slowed by, for example, degrading the visual input (Stanovich \& West, 1979).

In a series of experiments, Fischler and Bloom (1979) also found evidence for both facilitation and inhibition of word recognition by prior sentence contexts. Subjects in the context condition were given a sentence context to read (e.g., "Most cats see very well at __...") for $2 \mathrm{sec}$, followed by a lexical decision stimulus. On word trials, the test word could be a likely completion of the sentence (NIGHT), an unlikely but sematically accept able completion (BIRTH), or a semantically anomalous completion (COURT). A control group saw only a long row of Xs grouped like the words of a sentence. While substantial inhibition was observed for semantically anomalous test words, compared with the control group, facilitation was observed only for highly likely words, given as Cloze completions with a probability greater than $90 \%$. Latency for unlikely test words that created semantically acceptable sentences was not significantly different from that found in the control condition.

One way to apply the Posner and Snyder (1975) theory to these results is to explain both the inhibition and the facilitation as the effects of a focusing of attention on possible words that "make sense" of the context. This would inhibit responding to semantically anomalous completions. When the probability of any single word's occurring is low, facilitation on some trials is cancelled by inhibition on other trials. When the context allows very accurate prediction, a net facilitation is obtained.

Several problems arise with this interpretation. First, consider the facilitation for very likely words. The occurrence of such words during the session was itself an unlikely event, as it is with average reading materials (see Perfetti et al., 1979). It would seem inefficient, then, to actively anticipate particular words during reading. We would also expect that if subjects were anticipating particular words, then when the Cloze probability of a word was very high, few subjects would anticipate anything other than the highly likely words, and an inhibition for acceptable but unlikely words should be found. However, latency for unlikely words that followed contexts having highly likely completions ("dominant" contexts) was not different from either that of the neutral control or that of the other unlikely word trials.

Further evidence suggestive of automatic processing was found in a condition in which subjects were instructed to "ignore" any relation between the context 
and the test item. Despite these instructions, responses to highly likely test words were still facilitated. However, this interpretation assumes that subjects can use such instructions to control the deployment of attention to the sentence contexts. But the "ignore" instructions did not eliminate the inhibition of responses to semantically anomalous words, as it should have if the direction of attention in the task were fully under the reader's control (see also Spencer \& Halwes, Note 1). The inhibition was eliminated in an additional control condition in which test words were always anomalous completions of the context; latency to words in this condition did not differ from that of the neutral control. Apparently, the expectations that are produced by sentence contexts are influenced by the presence or absence of meaningful completions, but they are not influenced by the sub. jects' intentions alone.

\section{Rapid Presentation of Sentence Contexts}

In all of these studies using sentence contexts, subjects were given a substantial amount of time to process the context itself. The duration of the context was either self-paced (e.g., West \& Stanovich, 1978) or paced such that the context was shown for several seconds (Fischler \& Bloom, 1979). Given the remaining uncertainty about the extent to which the processing of sentence contexts can be automatic and given the previous success of temporal manipulations in separating auomatic and attentional processes (as in Neely, 1977), the present study was designed to examine the time course of sentential facilitation and inhibition of word recognition by varying the rate of presentation of the words of the context. We will first review some studies that suggest that sentences can be processed for meaning quite rapidly; then we will describe the possible outcomes of the experiment in the context of the Posner and Snyder (1975) theory.

In an experiment by Cosky and Gough (Note 2), the time available to read two- and four-word contexts was limited. Identification of a subsequent masked test word was compared with a no-context control. Contexts improved accuracy when presented for $500 \mathrm{msec}$, but not when presented for $250 \mathrm{msec}$. (There were no semantically anomalous test words used in the study.) However, the visual angle for the contexts was as great as $9 \mathrm{deg}$, which recent work (e.g., Rayner \& McConkie, 1976) has shown exceeds the visual angle at which subjects can get useful information about the identity of particular words. Moreover, it would be difficult to scan the words during a $250-\mathrm{msec}$ presentation.

There have been several demonstrations that when a series of words are presented singly in succession (referred to as rapid sequential visual presentation, or RSVP, by Forster, 1970), more words can be reported from sequences forming sentences than from random sequences. Jester (1966) reported such differences with presentation rates as high as 5 words/sec (wps), and
Pfafflin (1974), as high as 10 wps. Using a presentation rate of $16 \mathrm{wps}$, Forster and his colleagues found advantages in immediate recall for sentences vs. random word strings (Forster, 1970), for semantically normal vs. anomalous sentences' (Forster \& Ryder, 1971), and for one-clause vs. two-clause sentences (Forster, 1970).

In these RSVP studies, however, the advantages of sentence structure could be to some extent operative after presentation, as the subject tries to organize the sequence into more meaningful units for recall. In fact, Forster (1970) observed a significant tendency for the random strings to be reordered by subjects into grammatical sequences. Mitchell (1979) has also found effects of postpresentation events on recall of rapidly presented sentences. Potter, Kroll, and Harris (in press) found that both the ability to recall an RSVP sentence and the ability to judge whether a final word was plausible given the RSVP context were excellent at $12 \mathrm{wps}$. Despite the absence of an effect of sentence length, which Potter et al. suggest indicates that the meaning of the context is computed as presented, there were indications that, as in the above studies, a good deal of processing occurred at the end of the presentation: When a series of sentences was presented that formed a meaningful story, recall was improved by inserting a short $(1-\mathrm{sec})$ pause between sentences. Second, the plausibility judgments were rather slow (c. 1,300 msec), leaving more time for postpresentation factors to influence performance.

The present experiment used the RSVP technique to present a sentence context at rates varying from 4 wps to $28 \mathrm{wps}$ to determine the effects of speeded context on latency to make a lexical decision to a stimulus that immediately followed the context. The lower bound of 4 wps was chosen because, first, it is close to average reading speed (250-300 wpm) and, second, it is the RSVP equivalent, on the average, to the $2 \cdot \sec$ presentation of the entire sentence context used by Fischler and Bloom (1979). The upper bound was set at 28 wps to correspond to the smallest interval between prime and test at which we have found a semantic priming effect for individual word primes (Fischler \& Goodman, 1978). The design and materials used were identical to the initial experiments of Fischler and Bloom (1979). The primary purpose of the study was to determine the particular way in which context ceased to influence word recognition as the presentation rate increased.

\section{Choice of an Appropriate Control Condition}

The cost-benefit analysis introduced by Posner and Snyder (1975) requires the use of a neutral baseline against which the effects of a prime can be assessed. The assessment of facilitation and inhibition will be accurate only if this neutral condition controls for factors unre. lated to the content of prime and test that may affect response latency. The two factors of greatest concern are the alerting properties of the prime and the processing 
demands of the prime. Typically, alerting properties are controlled by using some "neutral" stimulus such as a row of $\mathrm{Xs}_{\mathrm{s}}$ as the baseline condition. This does not control for processing demands, and with primes as complex as sentences, this baseline may underestimate "true" neutral latency. The use of sequential presentation of the words of the context also changes the relative alerting properties of the context and control conditions, since the synatactic structure of the sentence context can be used by the subjects to better predict the occurrence of the test item. As presentation rate increases, this may result in an overestimation of "true" neutral latency by the "XX" control.

The present study includes the control condition used by Fischler and Bloom (1979), in which sentence contexts are presented as cues, but test words are always semantically anomalous completions. This condition controls for both the alerting and processing characteristics of sentences. Since the primary purpose of the study is to determine how presentation rate influences the context effects observed by Fischler and Bloom, the control condition is included here merely to replicate our earlier finding that the latency to acceptable but unlikely test words was identical to control latency, thus establishing the former as an appropriate baseline. Subsequent assessment of the benefits of seeing likely words and costs of seeing anomalous words can then be based on latency to unlikely words at each presentation rate.

\section{Automatic or Attentional Sentence Processing?}

The ability of subjects to process information in rapidly presented sentences suggests that both the facilitation for highly likely test words and the inhibition for anomalous test words will be obtained at least at the slowest presentation rate to be used, 4 wps. This ability is also suggestive of automatic processing. If the facilitation is the result of an automatic process, then it should be present at rates that eliminate the inhibition produced by anomalous words. Such an automatic process could be the convergence of activation spreading from the various content and function words of the sentence to a small set of possible test words.

On the other hand, if the priming effects of sentence context require attention, then the inhibition should persist at rates at least as fast as those at which facilitation is found. Further, if generating expectancies about particular words is more demanding than simply expecting the sentence to make sense, as Fischler and Bloom (1979) and Mitchell (1979) suggest, then the inhibition might actually persist at rates exceeding those at which the facilitation is eliminated.

\section{METHOD}

\section{Subjects}

Two hundred forty students from the introductory psychology classes at the University of Florida served as subjects in the study. Each subject was run individually in a session lasting about $15 \mathrm{~min}$. Thirty subjects served in each of the eight conditions (four presentation rates for both the control and context groups).

\section{Stimuli}

The set of 96 sentences used by Fischler and Bloom (1979) served as the stimulus materials in the present experiment Each sentence context consisted of a short (six-to eight-word) sentence frame missing the final word, with three possible corresponding final words. The primary response (PW) was the word given most of ten by 100 psychology students in a Cloze test (see Fischler \& Bloom, 1979). The probability of the primary response (defined as response dominance) ranged from .99 to .09 in a roughly rectangular distribution, with an average dominance of .53 . The final word could also be a semantically acceptable but unlikely (mean $p=.03$ ) completion of the sentence (UW, for unlikely words). Finally, the sentence could be completed by a syntactically acceptable but semantically anomalous word (AW). Mean length, number of syllables, and frequency (Kucera \& Francis, 1967) were matched across the three word types. For each of the resulting 288 words, a pronounceable nonword was generated ( $P N, U N$, and $A N$ ) by changing a single letter per syllable. A typical context-test set is shown in Figure 1.

\section{Apparatus}

The stimuli were presented on a Super Bee video terminal controlled by a PDP-8/e computer. Words were displayed in a white-on-black format, with letters written in a 5 by 7 dot matrix pattern. Contrast and brightness were adjusted at the start of the experiment to provide the clearest possible image. The vertical visual angle was $.3 \mathrm{deg}$ and the horizontal visual angle ranged from .8 to $4.0 \mathrm{deg}$.

\section{Design}

A given subject saw only one of the four presentation rates. Following Fischler and Bloom (1979), two groups of subjects were run at each presentation rate. For the context group, each of the six possible test items for a given sentence was equally likely to be presented. Each subject was shown each of the 96 sentence contexts once, followed by one of the six possible test items for each context. Test items were assigned to subjects randomly without replacement, so each set of six subjects formed a single replication of items. The order of sentences was completely randomized for each subject. Identical procedures were used for the control group, except that the sentence contexts and test items were re-paired so that the test items would never make sense, given the sentence context (see Figure 1).

\section{Procedure}

Subjects were told at the start of the sesssion that the experiment involved the reading of sentences under conditions of rapid presentation and deciding whether or not an item presented

\begin{tabular}{|c|c|c|}
\hline $\begin{array}{l}\text { Experimental } \\
\text { Condition }\end{array}$ & \multicolumn{2}{|c|}{$\begin{array}{c}\text { Example of } \\
\text { Sentence Context }\end{array}$} \\
\hline $\begin{array}{l}\text { Context } \\
\text { Control }\end{array}$ & \multicolumn{2}{|c|}{$\begin{array}{l}\text { She cleaned the dirt from her } \\
\text { He poured himself a glass of }\end{array}$} \\
\hline $\begin{array}{l}\text { Type of Lexical } \\
\text { Decision Test }\end{array}$ & Word & Nonword \\
\hline $\begin{array}{l}\text { Primary }(.99<\mathrm{p}<.09) \\
\text { Unlikely }(\text { mean } \mathrm{p}=.03) \\
\text { Anomalous }(\mathrm{p}=.00)\end{array}$ & $\begin{array}{l}\text { SHOES } \\
\text { HANDS } \\
\text { TERMS }\end{array}$ & $\begin{array}{l}\text { CHOES } \\
\text { MANDS } \\
\text { FERMS }\end{array}$ \\
\hline
\end{tabular}

Figure 1. Typical sentence contexts and corresponding lexical decision test items used in the experiment. 
at the end of the sentence was a word. In the context conditions, it was pointed out that if the test item was a word, it would usually make sense, given the meaning of the sentence context, much as it might in normal reading. In the control conditions, subjects were told that the experiment examined the effects of attempting to read a sentence per se on the ability to make the word-nonword decision. In both cases, the importance of trying to read the sentence context was stressed, and all subjects reported that they did attempt to read the contexts. Subjects were told to make the lexical decision as quickly and accurately as possible.

On each trial, the start of a sentence context was cued by a small asterisk, which was shown for $.5 \mathrm{sec}$. The cue, the words of the sentence context, and the test item were all shown leftjustified on the center line of the screen. The words of the context were shown singly in succession at rates of $4,12,20$, or 28 wps. Preliminary inspection of the display revealed that when the word was displayed until the next item was due to be presented, common letters in identical positions (e.g., the "a" in "man was") appeared to remain constant while the other letters changed. To avoid any potential disnuption of word processing, each word was displayed for only half of the effective presentation interval, and the screen was dark for the remaining time.

The test item was displayed as the final item in the sequence. The onset asynchrony of the test item and final context word was equal to that between any two successive context words. Thus as rate increased, the time available for sentence processing decreased equally from the onset of the first context word to the onset of the test item. In order to allow discrimination of context and test, the words of the context were presented in lowercase, whereas the lexical decision stimulus was shown in uppercase and remained visible until subjects pressed one of two response keys at opposite ends of the terminal keyboard. Half the subjects in each condition were told to respond with the forefinger of the left hand if the item was a word and with the forefinger of the right hand if a nonword was presented. The assignment of responses to keys was reversed for the other subjects. Three practice trials given at the start of the session served to familiarize the subjects with the task.

\section{RESULTS}

The mean latency for correct responses within each of the six test conditions was calculated for each subject and was treated as a single observation in the subsequent analyses. The mean latency for each of the six conditions across subjects is presented in Table 1 for each of the four presentation rates. Preliminary analyses showed that there was no effect of test type in the control condition at any presentation rate, so control latencies were collapsed across test type in Table 1 . In addition, control latencies for unlikely words did not differ from latencies to these items in the context group at any presentation rate. This replicates the results of Fischler and Bloom (1979) and validates the use of the UW condition as a within-subjects baseline for assessing facilitation and inhibition at a particular presentation rate.

A three-way analysis of variance was performed on the latencies of the context condition, with presentation rate as a between-subjects variable and test type (primary, unlikely, and anomalous) and response (word or nonword) as within-subjects variables. Given the large sample of items and contexts and the balancing of various item factors across test type, it seemed unlikely that any results would be unique to the materials used. Therefore, the analysis treated subjects as the only random effect.

The relation between the context and test item had a significant effect on response latency $[F(2,232)=33.22$, $\mathrm{p}<.0011$. The context effect was apparent for words but not for nonwords $[F(2,232)=52.70, p<.001]$, and it was somewhat greater at the lower rates than at the higher rates $[F(6,232)=4.01, p<.001]$. There was a significant main effect of presentation rate on latency $[F(3,116)=3.08, p<.05]$, with responses slower for both words and nonwords at the fastest presentation rate. Latency for words was substantially faster than that for nonwords $[F(1,116)=241.17, p<.001]$, with the largest difference at the fastest rate $[\mathrm{F}(3,116)=3.66$, $p<.05]$. The three-way interaction was also significant $[F(6,232)=4.20, p<.001]$.

The error rates across the various conditions are also presented in Table 1 . With few exceptions, the error rates vary directly with latency. No further analysis of errors was conducted.

\section{Assessment of Facilitation and Inhibition}

Using the latency in the UW condition as a baseline, facilitation and inhibition for the PW and AW conditions can be expressed as difference scores. Relative facilitation $(+)$ or inhibition $(-)$ is shown for each presentation rate in Table 2. Post hoc Newman-Keuls tests were performed on the difference scores, with the mean square error (MSe) derived by pooling the two MSes for interactions involving subjects and test type. The

Table 1

Mean Lexical Decision Latency (L) in Milliseconds and Percent Error (E) for Six Types of Sentence-Completion Stimuli Across Four Presentation Rates

\begin{tabular}{|c|c|c|c|c|c|c|c|c|c|c|c|c|c|c|c|c|}
\hline \multirow{4}{*}{$\begin{array}{l}\text { Type of } \\
\text { Completion }\end{array}$} & \multicolumn{16}{|c|}{ Presentation Rate (in Words per Second) } \\
\hline & \multicolumn{8}{|c|}{ Words } & \multicolumn{8}{|c|}{ Nonwords } \\
\hline & \multicolumn{2}{|c|}{4} & \multicolumn{2}{|c|}{12} & \multicolumn{2}{|c|}{20} & \multicolumn{2}{|c|}{28} & \multicolumn{2}{|c|}{4} & \multicolumn{2}{|c|}{12} & \multicolumn{2}{|c|}{20} & \multicolumn{2}{|c|}{28} \\
\hline & L & $\mathrm{E}$ & $\mathbf{L}$ & E & $\mathrm{L}$ & $\mathrm{E}$ & L & $\mathrm{E}$ & L & $\mathrm{E}$ & $\mathbf{L}$ & $\mathrm{E}$ & $\mathrm{L}$ & $\mathbf{E}$ & L & E \\
\hline $\begin{array}{l}\text { Primary } \\
\text { Unlikely } \\
\text { Anomalous }\end{array}$ & $\begin{array}{l}669 \\
696 \\
776\end{array}$ & $\begin{array}{l}3.3 \\
4.8 \\
8.1\end{array}$ & $\begin{array}{l}644 \\
678 \\
788\end{array}$ & $\begin{array}{l}3.3 \\
4.4 \\
8.3\end{array}$ & $\begin{array}{l}668 \\
679 \\
722\end{array}$ & $\begin{array}{l}3.7 \\
3.5 \\
5.6\end{array}$ & $\begin{array}{l}739 \\
732 \\
791\end{array}$ & $\begin{array}{l}5.4 \\
4.8 \\
5.2\end{array}$ & $\begin{array}{l}821 \\
823 \\
804\end{array}$ & $\begin{array}{l}8.1 \\
6.5 \\
9.2\end{array}$ & $\begin{array}{l}795 \\
829 \\
799\end{array}$ & $\begin{array}{l}8.1 \\
7.9 \\
6.5\end{array}$ & $\begin{array}{l}816 \\
804 \\
792\end{array}$ & $\begin{array}{r}7.1 \\
7.7 \\
10.2\end{array}$ & $\begin{array}{l}927 \\
894 \\
936\end{array}$ & $\begin{array}{l}10.6 \\
11.0 \\
10.8\end{array}$ \\
\hline Control & 725 & 4.6 & 678 & 5.5 & 706 & 3.8 & 683 & 4.4 & 837 & 6.3 & 783 & 9.3 & 882 & 9.2 & 835 & 9.2 \\
\hline
\end{tabular}

Note-In the control condition, the test item was always an anomalous completion of the context. 
results of the Newman-Keuls tests are also given in Table 2.

The pattern of results is quite clear: A small but sig. nificant facilitation for the PW condition was obtained at 4 and 12 wps; no facilitation was obtained at the two faster rates. In contrast, a significant inhibition for $\mathrm{AW}$ trials was observed at all presentation rates. The inhibition was smaller at 20 and 28 wps than at 4 and 12 wps.

\section{Effects of Dominance}

Latencies for the 12 contexts with the highest dominance for the primary responses (mean $p=.92$ ) were compared with the remainder of the contexts for PW and PN trials, as shown in Table 3. The data from Fischler and Bloom (1979) are presented for comparison. In contrast to the substantial advantage for the highly likely test words vs. other primary test words that was obtained in the simultaneous-context experiments, the "high-dominant" test words were never responded to more quickly than were the other PW words at any presentation rate. Inclusion of the 12 sentences next highest in dominance did little to alter this pattern. In contrast with simultaneous presentation, then, there was no special advantage of being shown a test word that was highly likely given the context, even at the slowest rates.

There was a tendency for dominant tests on PN trials (e.g., "He mailed the letter without a STIMP.") to have longer latencies and higher error rates than tests for less dominant contexts, but, oddly, this tendency was greater at the faster presentation rates. The significance of this pattern is unclear.

\section{Sentence Complexity}

One factor that should affect the processing demands of a given sentence context is syntactic complexity. The sentences were originally designed to include a variety of sentence structures, but no systematic variation of linguistic structure was attempted. Therefore, the set of sentence contexts, completed with the primary response words, was given to a professor of linguistics at the University of Florida (Jean Casagrande), who judged the 12 most and 12 least syntactically complex sentences. These are presented in the Appendix. Inspection of the complex sentences reveals several embedded clauses, complex verbs (e.g., "warned"), and inverted constructions.

Since the facilitation for PW trials was small at the slower rates and absent at the faster rates, the effects of sentence complexity were determined by observing the size of the inhibitory effect for AW trials compared with the UW trials within the context condition. Mean response latency for simple vs. complex sentences is shown in Table 4. A consistent pattern was seen: At 4 and $12 \mathrm{wps}$, both types of sentences produced substantially slower latencies for AW trials than for UW trials. However, at 20 and particularly at $28 \mathrm{wps}$, the simple sentences continued to show this difference, whereas the inhibition for complex sentences became nonsignificant at 20 and $28 \mathrm{wps}$.

\section{Item Associations Between Context and Test}

Although the stimulus materials were selected to avoid high levels of association between the context and

Table 2

Pairwise Comparisons (P) and Results of Newman-Keuls Tests (q) for Each of Four Presentation Rates

\begin{tabular}{|c|c|c|c|c|c|c|c|c|}
\hline \multirow{3}{*}{$\begin{array}{c}\text { Type of } \\
\text { Comparison }\end{array}$} & \multicolumn{8}{|c|}{ Presentation Rate (in Words per Second) } \\
\hline & \multicolumn{2}{|c|}{4} & \multicolumn{2}{|c|}{12} & \multicolumn{2}{|c|}{20} & \multicolumn{2}{|c|}{28} \\
\hline & $\mathbf{P}$ & $q$ & $\mathrm{P}$ & $q$ & $\mathbf{P}$ & $q$ & $\mathbf{P}$ & $q$ \\
\hline $\begin{array}{l}\text { UW-PW } \\
\text { UW-AW }\end{array}$ & $\begin{array}{l}+27 \\
-80\end{array}$ & $\begin{array}{l}2.58 \dagger \\
7.66^{*}\end{array}$ & $\begin{array}{l}+34 \\
-110\end{array}$ & $\begin{array}{c}3.25^{* *} \\
10.53^{*}\end{array}$ & $\begin{array}{l}+11 \\
-43\end{array}$ & $\begin{array}{l}1.05 \\
4.11^{*}\end{array}$ & $\begin{array}{l}-7 \\
-59\end{array}$ & $\begin{array}{c}.67 \\
5.65^{*}\end{array}$ \\
\hline
\end{tabular}

Note $-U W$ is used as a baseline to assess facilitation $(+)$ and inhibition $(-1 . P W=$ primary words; $U W=$ unlikely words; $A W=$ anoma lous words. $\quad * p<.01 . \quad * * p<.05 . \quad t_{p}<.10$.

Table 3

Mean Lexical Decision Latency (L) in Milliseconds and Error Rate (E) for High-Dominant vs. All Other Sentence Completions

\begin{tabular}{|c|c|c|c|c|c|c|c|c|c|c|}
\hline & \multicolumn{10}{|c|}{ Presentation Rate (in Words per Second) } \\
\hline & \multicolumn{2}{|c|}{$S^{*}$} & \multicolumn{2}{|c|}{4} & \multicolumn{2}{|c|}{12} & \multicolumn{2}{|c|}{20} & \multicolumn{2}{|c|}{28} \\
\hline & $\mathbf{L}$ & E & $\mathrm{L}$ & E & L & $\mathrm{E}$ & $\mathbf{L}$ & $\mathrm{E}$ & $\mathbf{L}$ & $\mathrm{E}$ \\
\hline & \multicolumn{10}{|c|}{ Primary Words } \\
\hline High-Dominant & 553 & .0 & 684 & 1.6 & 646 & 3.2 & 707 & 10.0 & 711 & 3.3 \\
\hline \multirow[t]{2}{*}{ All Others } & 641 & 3.0 & 667 & 3.5 & 644 & 3.3 & 662 & 2.8 & 742 & 5.7 \\
\hline & \multicolumn{10}{|c|}{ Primary Nonwords } \\
\hline High-Dominant & 784 & 15.0 & 843 & 11.0 & 824 & 16.7 & 859 & 25.0 & 986 & 15.0 \\
\hline All Others & 802 & 6.0 & 818 & 7.7 & 791 & 6.9 & 810 & 4.5 & 919 & 10.0 \\
\hline
\end{tabular}

Note-Latencies presented are for the context condition only. For high-dominant sentence completions, $p=.92(n=12$ sentences). For all other sentence completions, $.78<p<.19(n=84$ sentences). $\quad *$ Data for simultaneous presentation of context words from Fischler and Bloom (1979). 
Table 4

Mean Lexical Decision Latency for Anomalous (AW) and Unlikely (UW) Words Following Syntactically Simple vs. Complex Sentence Contexts

\begin{tabular}{|c|c|c|c|c|c|c|c|c|}
\hline \multirow{3}{*}{$\begin{array}{c}\text { Type of } \\
\text { Test }\end{array}$} & \multicolumn{8}{|c|}{ Presentation Rate (in Words per Second) } \\
\hline & \multicolumn{4}{|c|}{ Simple Sentences } & \multicolumn{4}{|c|}{ Complex Sentences } \\
\hline & 4 & 12 & 20 & 28 & 4 & 12 & 20 & 28 \\
\hline $\begin{array}{l}\mathbf{A W} \\
\text { UW } \\
\text { UW-AW }\end{array}$ & $\begin{array}{r}859 \\
731 \\
-128\end{array}$ & $\begin{array}{l}825 \\
726 \\
-99\end{array}$ & $\begin{array}{r}748 \\
653 \\
-95\end{array}$ & $\begin{array}{l}809 \\
743 \\
-66\end{array}$ & $\begin{array}{r}796 \\
667 \\
-129\end{array}$ & $\begin{array}{r}812 \\
676 \\
-136\end{array}$ & $\begin{array}{l}707 \\
663 \\
-44\end{array}$ & $\begin{array}{l}703 \\
730 \\
+27\end{array}$ \\
\hline$t(11)$ & $3.54^{*}$ & $1.72 \dagger$ & $1.95 * *$ & 1.01 & $2.43 * *$ & $3.87^{*}$ & .79 & .55 \\
\hline
\end{tabular}

Note-Since the comparison of $A W$ and UW for a particular subset of sentences was between both subjects and test words, the difference needed to be quite large to reach significance (see Appendix). $\quad{ }^{*} p<.01 . \quad{ }^{* *} p<.05 . \quad$ tp $<.10$.

the test words, a reexamination of the sentences revealed a number of sets that may have involved at least some associative connections between particular words of the context and the test word. (Compare, for example, "He hit the nail into the WOOD" with "Billy hit his sister on the HEAD.")

Thirty such sentences were identified by the experimenters. The "associated" contexts showed no greater facilitation than the "nonassociated" contexts for PW trials at any rate; the largest difference in the facilitation in the appropriate direction was $9 \mathrm{msec}$. For AW trials, the "associated" contexts showed latencies somewhat faster than those for "nonassociated" contexts at the slowest rates, and they were essentially identical at the two fastest rates. In summary, there was no evidence that particular word associations influenced response latency at any speed.

\section{DISCUSSION}

Presentation of a sentence context under RSVP conditions has been shown to have systematic effects on the ability to recognize words presented as completions of that context with presentation rates of up to 28 wps. The major effect was that response time to words that produced semantically anomalous sentences was slower than that to words that produced acceptable sentences at all presentation rates used. In contrast, presentation of likely response words produced a marginal facilitation, compared with unlikely but acceptable words, at the two slower rates and none at all at the two faster rates. The major difference between the present RSVP data at the slower presentation rates and the simultaneous condition of Fischler and Bloom (1979) is that words that were very likely completions of the sentence were here recognized no faster than were less dominant primary words.

Several of the results suggest that attention is required to process sentence contexts to the point at which recognition of successive words can be affected. First, facilitation for likely words was always accompanied by an inhibition for anomalous test words. The presence of costs along with benefits can be interpreted within the
Posner and Snyder (1975) theory as implying attentional involvement in the processing of contexts. The persistence of inhibition in the absence of facilitation at the faster presentation rates is also consistent with an attentional interpretation. Neely $(1977$, p. 245) discussed a similar temporal pattern for attentional effects with single-word primes, and he argues that attentional inhibition should develop more rapidly than does attentional facilitation.

The absence of facilitation for the most likely test words, even at the slowest rate, also suggests that the dominance effect observed by Fischler and Bloom (1979) was the result of an attentional process that was effective only when the entire context could be inspected for several seconds and the context overwhelmingly suggested a particular test word. Anticipation of particular words would be an inefficient strategy for a skilled reader, since in normal prose, content words are rarely very predictable and word recognition itself is highly automated. Effects of predictability have also been small or absent in other studies using RSVP procedures (Forster, 1970; also see Mitchell \& Green, 1978).

If the processing of contexts demands attention, then we should expect the capacity of the attentional system in this task to be exceeded at some point. Two additional aspects of the data suggest that at $28 \mathrm{wps}$, this point is being reached. First, for both words and nonwords, latencies in the 28-wps condition were longer than those at any of the slower rates. This change was not due to less adequate alerting properties of the more rapidly presented contexts, since no such change was observed in the control condition. The presentation of the test word immediately upon completion of the context allowed for little of the postpresentation integrative or reconstructive processing that may occur with RSVP studies of sentence recall. The increased latency suggests that the computation of the general meaning of the sentence is beginning to lag the real-time presentation rate at $28 \mathrm{wps}$. More support for this argument comes from the fact that subjects with slower overall mean latencies tended to show greater inhibition on $\mathrm{AW}$ trials $(\mathrm{r}=+.58, \mathrm{p}<.01)$.

We also observed that at 20 wps and particularly 
at $28 \mathrm{wps}$, inhibition persisted for syntactically simple sentences but not for syntactically complex ones. Assuming that the complex sentences make more demands on processing, this result also suggests that the limits of sentence processing are being reached at the fastest presentation rate.

So far, we have argued in favor of an attentional involvement in sentence processing in this task. But the inhibition of responding on which this argument rests has two of the characteristics of automatic processes described by Posner and Snyder (1975): It is elicited extremely rapidly, and it is relatively difficult to avoid. The question, then, is whether this inhibition could be explained as the result of an automatic process. while conserving the distinction between automatic and attentional mechanisms, as drawn by Posner and Snyder.

There are circumstances in which an automatic process can produce inhibition of certain types of responses (Posner \& Snyder, 1975). One example is the Stroop interference effect, in which latency to name the color of a printed word is slowed if the word is the name of a different color (Dyer, 1973; see also Neill, 1977). Here, the name of the color word is elicited automatically, and, despite any intentions to ignore the irrelevant information, it interferes with production of the naming response. The critical feature seems to be that the automatically elicited response is a potentially correct response in the task.

There are several reasons for supposing that the inhibitory effects of sentence contexts are not analogous to these automatic interference effects. First, the name of the colored word (or in some cases, words associated to a color different from the correct one) is a specific response elicited by that item, whereas the range of words potentially inhibited by the sentence context is very great-all those words not conserving the context's meaning. Second, Stroop interference arises because the required and the interfering responses are incompatible; in contrast, the correct overt response is the same for semantically anomalous and acceptable words. Finally, if such an automatic interference were occurring, a similar effect should be found for singleword primes at similar prime-test intervals. That is, seeing the word "cat" should inhibit responding to semantically unrelated words (e.g., "key") because of interference with automatically elicited related words such as "dog."

If the inhibition is not a form of interference from particular responses that are automatically elicited, how should it then be characterized? As suggested in the introduction, we believe that the development of the expectancies that lead to the inhibition of semantically anomalous words has become, with a great deal of experience, rapid and difficult to overcome. Rather than a neat dichotomy between processes that require a limited, conscious, central capacity and those that do not, the application of the Posner and Snyder (1975) theory to tasks such as reading seems to call for a more continuous model of how limited resources can be utilized more efficiently with practice (Norman \& Bobrow, 1975). Many apparently "automatic" tasks can be shown to involve attentional effort (Kahneman, 1973), and recent work on divided attention suggests that two very complex tasks can be successfully carried out concurrently, if sufficient practice is given (Spelke, Hirst, \& Neisser, 1976).

The rapid accrual of semantic information has also been demonstrated by others in a variety of paradigms (e.g., Allport, 1977; Carr \& Bacharach, 1976; Marcel \& Patterson, 1978), and it has been argued that the extraction of meaning from a stimulus may precede conscious identification. Subjects given the fastest presentation rates in the present study reported that they were rarely able to fully comprehend the sentence context and were able to identify only one or two words from the sequence.

Still, one might ask whether we are actually observing "sentence processing" at these high rates, in view of the subject reports. Estimates of the limits of sentence processing speed depend, of course, on what kinds of information the subject is required to utilize in the task. Single words may be recognized with $50 \mathrm{msec}$ or less of effective visual exposure. Searching for a word in an RSVP series is also quite efficient, with detection accuracy above chance for rates of up to $35-40 \mathrm{wps}$ (Fischler, Note 3). The ability to discriminate the order of presentation of two items in an RSVP series begins to fail at about 10 wps, however (Lawrence, 1971). All these rates are substantially faster than the rate at which most readers feel comfortable in comprehending sentences and relating them to prior information, which is about $300 \mathrm{wpm}$, or 5 wps.

Since at 28 wps, each word is displayed with an onset asynchrony of $36 \mathrm{msec}(18 \mathrm{msec}$ on, $18 \mathrm{msec}$ off), one might suppose that the priming effects at this speed are due simply to some additive combination of effects of the individual words constituting the sentence. The analysis of sentences with words associated to test words produced latencies no different from those obtained from other contexts, but we mentioned earlier the possibility of activity from several words intersecting at some memory location. This account can be rejected for several reasons. First, such a process should produce an automatic facilitation, and we found no evidence for this. Second, if only word-to-word effects were present, it is unclear why complexity at the sentential level, which is characterized by the particular syntactic and semantic structure of the sequence of words, should differentially affect the size of contextual priming. Third, the inhibition is of words anomalous to the sentence meaning, which can be arbitrarily related to the individual words of the sentence; it is hard to imagine a strictly lexical priming process that would account for the inhibition of noncorporeal words following "Billy 
hit his sister on the ...."While priming among particular words within a sequence surely occurs (see Kleiman, 1977), it therefore seems to be an inadequate mechanism for explaining the present results.

The effects of semantic anomaly are therefore likely to be produced at levels "deeper" than that needed for individual word processing. Semantic effects of sentence context on word recognition, particularly at the high rates of presentation used here, would thus seem incompatible with strictly hierarchical or "bottom-up" models of sentence comprehension, in which the analysis of meaning occurs at a final stage of processing. Over the years, the notion that meaning plays a more concurrent role in sentence perception has surfaced a number of times (e.g., Pierce \& Karlin, 1957), most recently as the more fully interactive models of reading being realized as computer simulations (e.g., Rumelhart, 1977). In these models, stimulus information is used to construct a "picture" of the message related by the sentence, with various levels of analysis accumulating information in parallel and the message being understood when enough information becomes available across levels to uniquely define the message.

As Allport (1979) has pointed out, one major theoretical choice to be made with such models is whether the expectancies that develop as evidence accumulates at various levels (e.g., Rumelhart's, 1977, "hypotheses" in HEARSAY II) take the form of active predictions that are consciously attended to (e.g., as in the work of Reddy \& Newell, 1974) or whether these expectancies remain preattentive or "latent" (e.g., as in Reisbeck, 1975). Allport (1979) suggests that it would be more efficient to have such expectancies remain latent, pending confirmatory evidence, since otherwise they would cause precisely the kind of inhibitory disruption observed in our sentence-priming experiments.

We have suggested, however, that such a disruption would be of value to the reader, as a signal that perception or comprehension has failed, and that some reanalysis is called for. Disruption caused by semantic anomaly was also clearly seen when subjects were allowed to pace the presentation of prose given in threeword chunks (Mitchell \& Green, 1978). Semantically anomalous word completions also cause a unique pattern in brain potentials, discernible as early as $200 \mathrm{msec}$ from the onset of the anomalous word (Kutas \& Hillyard, in press). Moreover, the expectancies regarding particular words, which with material of normal redundancy would be quite disruptive, are just the ones that subjects seem to avoid developing. Our results suggest that the expectancies related to sentence meaning are best characterized as "active" in the sense of requiring attentional resources, but "latent" in the sense of not being consciously directed or perceived. Awareness of expectancies is produced largely when they are disconfirmed.

A final question concerns the applicability of the data derived from the RSVP paradigm to normal reading conditions. RSVP is not particularly disruptive of comprehension; in fact, Potter et al. (in press) have shown recall and comprehension of RSVP contexts to be somewhat better than that for simultaneously presented contexts read for equal amounts of time. The RSVP procedure does apparently alter certain aspects of sentence processing, as evidenced by the absence of the dominance effect observed by Fischler and Bloom (1979) for any presentation rate here. But, as we have argued, the role of dominance may not be significant in normal reading, and we concur with Potter et al. that RSVP processing is similar in essential respects to that which occurs in normal reading.

In summary, our experiments on sentence contexts indicate that they have systematic effects on the ability to recognize a word as a word, that these effects can be interpreted less as a facilitation of particularly likely words than as an inhibition of semantically inappropriate words, and that this inhibition is apparently generated very rapidly. The speeds at which contextual effects were obtained suggests that the general meaning of a sentence can be obtained and used to direct attention with little apparent effort or conscious comprehension. At least some aspects of sentence processing, then, are able to keep pace with rapid word recognition as high levels of reading skill develop.

\section{REFERENCE NOTES}

1. Spencer, N. J., \& Halwes, T. Shifts in categorical speech perception in sentence contexts. Paper presented at the meeting of the American Psychological Association, New York, September 1979.

2. Cosky, M., \& Gough, P. B. The effect of context on word recognition. Paper presented at the meeting of the Midwestern Psychological Association, Chicago, May 1973.

3. Fischler, I. Detection of single-word targets in lists of rapidly presented words. Unpublished study, Stanford University, 1972.

\section{REFERENCES}

Allport, D. A. On knowing the meaning of words we are unable to report: The effects of visual masking. In S. Dornic (Ed), Attention and performance VI. Hillsdale, N.J: Erlbaum, 1977.

Allpont, D. A. Conscious and unconscious cognition: A computational metaphor for the mechanism of attention and integration. In L. Nilsson (Ed.), Perspectives on memory research. Hillsdale, N.J: Erlbaum, 1979.

CARr, T. H., \& Bacharach, U. R. Perceptual tuning and conscious attention: Systems of input regulation in visual information processing. Cognition, 1976, 4, 281-302.

DYE R, F. N. The Stroop phenomenon and its use in the study of perceptual, cognitive, and response processes. Memory \& Cognition, 1973, 1, 106-120.

Fischle R, I. Associative facilitation without expectancy in a lexicall decision task. Journal of Experimental Psychology: Human Perception and Performance, 1977, 3, 18-26.

Fischle R, I., \& Bloom, P. A. Automatic and attentional processes in the effects of sentence contexts on word recognition. Journal of Verbal Learning and Verbal Behavior, 1979, 18, 1-20.

Fischler, I., \& Goodman, G. O. Latency of associative activation in memory. Journal of Experimental Psychology: Human Perception and Performance, 1978, 4, 455-470.

Forster, K. I. Visual perception of rapidly presented word sequences of varying complexity. Perception \& Psychophysics, $1970,8,215-221$. 
Forster, K. I., \& Ryder, L. A. Perceiving the structure and meaning of sentences. Journal of Verbal Learning and Verbal Behavior, 1971, 10, 285-296.

JESTE R, R. E. Comprehension of connected meaningful discourse as a function of individual differences and rate and modality of presentation. Unpublished doctoral dissertation, University of Utah, 1966

Kahneman, D. Attention and effort. Englewood Cliffs, N.J: Prentice-Hall, 1973

KLEIMAN, G. M. The effect of previous context on reading individual words. Unpublished doctoral dissertation, Stanford University, 1977.

KuČera, H., \& Francis, W. N. Computational analysis of presentday American English. Providence, R.I: Brown University Press, 1967.

Kutas, M, \& Hillyard, S. A. Reading senseless sentences: Brain potentials reflect semantic incongruity. Science, in press.

LaBerge, D. Perceptual learning and attention. In W. K. Estes (Ed.), Handbook of learning and cognitive processes (Vol. 4). Hillsdale, N. J: Erlbaum, 1976.

LAWRENCE, D. H. Two studies of visual search for word targets with controlled rates of presentation. Perception \& Psychophysics, 1971, 10, 85-89.

Marcel, A. J., \& Patterson, K. E. Word recognition and production: Reciprocity in clinical and normal studies. In J. Requin (Ed.), Attention and performance VII. Hillsdale, N.J: Erlbaum, 1978.

Meyer, D. E., \& Schvaneveldt, R. W. Facilitation in recognizing pairs of words: Evidence of a dependence between retrieval operations. Journal of Experimental Psychology, 1971, 90, 227-234.

Mitchels, D. C. The locus of the experimental effects in the rapid sequential visual presentation (RSVP) task. Perception \& Psychophysics, 1979, 25, 143-149.

Mitchell, D. C., \& Green, D. W. The effects of context and content on immediate processing in reading. Quarterly Journal of Experimental Psychology, 1978, 30, 609-636.

Morton, J. The effects of context on the visual duration threshold for words. British Journal of Psychology, 1964, 55, 165-180.

NEELY, J. H. Semantic priming and retrieval from lexical memory: Roles of inhibitionless spreading activation and limited-capacity attention. Journal of Experimental Psychology: General, 1977, $106,226-254$

NEILL, W. T. Inhibitory and facilitatory processes in selective attention. Journal of Experimental Psychologv: Human Perception and Performance, 1977, 3, 444-450.

Norman, D. A., \& Bobrow, D. G. On data-limited and resourcelimited processes. Cognitive Psychology, 1975, 7, 44-64.

Perfetti, C. R., Goldman, S. R., \& Hogaboam, T. W. Reading skill and the identification of words in discourse context. Memory \& Cognition, 1979, 7, 273-282.

Pfafflin, S. M. The total time hypothesis, recall strategies, and memory for rapidly presented word strings. Memory \& Cognition, 1974, 2, 236-240.

Pierce, J. R., \& Kari. IN, J. E. Reading rates and the information rate of a human channel. Bell Systems Technical Journal, 1957, 36, 497-516.

Posner, M. I., \& Snyder, C. R. R. Attention and cognitive control. In R. L. Solso (Ed.), Information processing and cognition. Hillsdale, N.J: Erlbaum, 1975.

Potter, M. C., Kroll. J. F., \& Harris, C. Comprehension and memory in rapid sequential reading. In R. S. Nickerson (Ed.), Attention and performance VIII. Hillsdale, N.J: Erlbaum, in press.
Rayner, K., \& MCConkit, G. W. What guides a reader's eyemovements. Vision Research, 1976, 16, 829-838.

REDDY, R., \& NEWELL, A. Knowledge and its representation in a speech understanding system. In L. W. Gregg (Ed.), Knowledge and cognition. Potomac, Md: Erlbaum, 1974.

RIESBEck, C. K. Conceptual analysis. In R. C. Schank (Ed.), Conceptual information processing. Amsterdam: North Holland, 1975.

Rumelhart, D. E. Toward an interactive model of reading. In S. Dornic (Ed.), Attention and performance VI. Hillsdale, N.J: Erlbaum, 1977

Schneider, W., \& Shiffrin. R. M. Controlled and automatic human information processing: 1. Detection, search and attention. Psychological Review, 1977, 84, 1-66.

Schuberth, R. E., \& Eimas, P. D. Effects of context on the classification of words and nonwords. Journal of Experimental Psychology: Human Perception and Performance, 1977, 3, $27-36$.

Spelke, E., Hirst, W., \& Neisser, U. Skills of divided attention. Cognition, 1976, 4, 215-230

Stanovici, K. E., \& West, R. F. Mechanisms of sentence context effects in reading: Automatic activation and conscious attention. Memory \& Cognition, 1979, 7, 77-85.

TAYLOR, W. L. "Cloze" procedure: A new tool for measuring readability. Journalism Quarterly, 1953, 30, 415.

Tulving, E., \& Gold, C. Stimulus information and contextua information as determinants of tachistoscopic recognition of words. Journal of Experimental Psychology, 1963, 66, 319-327.

Tweedy, J. R., Lapinski, R. H., \& Schvaneveldt, R. W. Semantic-context effects on word recognition: Influence of varying the proportion of items presented in an appropriate context. Memorv \& Cognition, 1977, 5, 84-89.

West, R. F.. \& Stanovich, K. E. Automatic contextual facilitation in readers of three ages. Child Development, 1978, 49 $717-727$.

\section{APPENDIX}

\section{Sentences Rated as Syntactically Simple}

(1) The hungry bear found some stale bread. (2) The death of his dog was a great shock. (3) Billy hit his sister on the head. (4) He drove the nail into the wood. (5) Lois is taller than most girls. (6) Plants will not grow in dry soil. (7) He mailed the letter without a stamp. (8) Jim had learned the special passage by heart. (9) In the first space enter your name. (10) They rested under a tree in the shade. (11) He bought them in the candy store. (12) She called her husband at his office.

\section{Sentences Rated as Syntactically Complex}

(1) Three people were killed in a major highway accident. (2) The judge warned about the dangers of drinking. (3) The person who caught the thief deserves our thanks. (4) The surgeon tried vainly to save his patient. (5) The car stalled because the engine failed to start. (6) Rushing out he forgot to take his coat. (7) They wanted their parents to come home. (8) The surface of the water was nice and smooth. (9) George could not believe his son stole a car. (10) The storm made the air damp and cold (11) Few had the nerve to take the needed shot. (12) The police had never seen a man so drunk.

(Received for publication June 18, 1979; revision accepted January 9,1980 .) 